\title{
FOREIGN LANGUAGE LEARNING AND TEACHING ENJOYMENT: TEACHERS' PERSPECTIVES
}

\author{
EWELINA MIERZWA \\ Department of Applied Linguistics,Opole University, \\ pl. Kopernika 11, 45-040 Opole, Poland \\ E-mail address: ewciamierzwa@gmail.com \\ ORCID: https://orcid.org/0000-0002-2653-7768
}

\begin{abstract}
Aim. The primary objective of the present study was to investigate the level of Foreign Language (FL) learning Enjoyment and Foreign Language (FL) teaching Enjoyment experienced by FL teachers in Poland. The secondary aim was to investigate the sources of enjoyment.

Methods. The informants of the study were Polish educators teaching foreign languages at different educational levels. Standard descriptive and inferential statistics were used to report means, median and standard deviation for sociodemographic and baseline characteristics of the sample. The t-Test and one-way ANOVA were used to show mean differences in the score data.

Results. The results of the study revealed that teachers experienced a relatively high level of both FL learning Enjoyment and FL teaching Enjoyment, regardless of independent variables (e.g. place of residence, level of education, language being taught). The result revealed a significant gender difference in FL learning Enjoyment in favour of females, while there was no gender difference in FL teaching Enjoyment. A qualitative analysis of participants' emotional experiences in the FL classroom confirmed previous research on FLE to a certain degree. That is, FLE is more related to learner-internal and teacherspecific variables than to the behaviour of peers and the atmosphere in the classroom.

Conclusion. The originality of the present study lies in the choice of a mixed-methods approach (qualitative and quantitative data) using a relatively large sample in a field characterised by case studies. To the best of my knowledge, this is the first study on foreign language enjoyment among teachers within the Polish educational context.

Key Words: foreign language enjoyment, foreign language teachers, enjoyment, SLA, gender differences, positive psychology
\end{abstract}

\section{INTRODUCTION}

A cademic success, or lack of it, may arouse a plethora of different emotions in students, which in consequence may affect their performance and govern their future directions (Pekrun, \& Perry, 2014). The way both stu- 
dents and their educators respond to emotions may affect learners' education in ways that may later on translate into their social, emotional and eventually cognitive development. Thus, broadening the knowledge on emotions experienced in the foreign language classroom is well worth the effort. It is safe to say that for approximately four decades the research on emotions has focused primarily on negative emotions and, more specifically, on language anxiety (Daubney, Dewaele, \& Gkonou, 2017). This situation has changed with the advent of positive psychology. In recent years, the attention of researchers in the field of second language acquisition (SLA), language educators and teachers has been shifted into positive emotions (MacIntyre, \& Mercer, 2014; MacIntyre, 2016; MacIntyre, Gregersen, \& Mercer, 2016). Among the gamut of positive emotions experienced in the foreign language classroom, enjoyment deserves a thorough investigation due to the critical role it serves in the achievement setting (Piechurska-Kuciel, 2017). Although in recent years there has been an increasing attention paid to investigating the role of foreign language enjoyment among students (Dewaele, \& MacIntyre, 2014; Dewaele, \& MacIntyre, 2016; Piechurska-Kuciel, 2017; Dewaele, Witney, Saito, \& Dewaele, 2017; Dewaele, Franco, \& Saito, 2019), little is known about this particular emotion from the perspective of foreign language educators. This comes as a slight disappointment, as teachers play a pivotal role in the aforementioned process. Thus, the primary aim of this study is to investigate foreign language enjoyment from the perspective of FL teachers.

\section{LITERATURE REVIEW ON ENJOYMENT}

Enjoyment can be described as an example of positive achievement emotions (Pekrun, 2006). Learners who experience enjoyment feel in control of the achievement activities they are involved in and/or perceive activities' outcomes as personally significant (Pekrun, Frenzel, \& Goetz, 2007). In this vein, learning enjoyment can be perceived as the pleasure experienced once a learner appreciates the learning material (positive appraisal) and feels capable of dealing with and completing the activity he/she is faced with (control). Thus, enjoyment is believed to be of the utmost importance for the subsequent sense of satisfaction, which complements academic achievement (Ainley, \& Hidi, 2014; Piechurska-Kuciel, 2017). Based on the assumption that achievement emotions are domain-specific, it is fair to say that enjoyment is related to specific subject areas, e.g. learning a foreign language (FL), which appears to be the process particularly vulnerable to the deleterious effects of negative emotions. Nevertheless, recent trends in positive psychology have led to a proliferation of studies designed to promote the importance of foreign language learning being charged with positive emotions and which perceive positive emotions as an amplifier and a driving force behind second language acquisition (SLA) (Dewaele, \& MacIntyre, 2014; Oxford, 2015; Dewaele et al., 2017). 
As a multidimensional construct, enjoyment embraces five components: affective, cognitive, motivational, expressive and physiological (Hagenauer, \& Hascher, 2014), the first three of which deserve special attention. Referring to the FL environment, it is reasonable to believe that the affective component of enjoyment refers to the sense of joy experienced while learning a FL, whereas the cognitive one to a positive evaluation of the situation which the FL learner is engaged in. As such, FLE might be described as the feeling of excitement and/ or a spontaneous joy derived from participation in a novel and challenging foreign language activity (affective component), which arouses learners' curiosity and generates interest (cognitive component). Thus, it is reasonable to believe that enjoyment actively and positively stimulates learners in the foreign language classroom, as it may play a fundamental role in the cognitive processes which are instrumental for learning in general and FL learning in particular, e.g. heightened attention, memory and problem solving (Fredrickson, 2001; Fredrickson, 2004; Pekrun, 2011; Oades-Sese, \& Lewis, 2014). Subsequently, the motivational component of enjoyment signifies the students' willingness to sustain that positive experience, propelling them into action and motivating them to take up future FL challenges. According to Dewaele and MacIntyre (2014), FLE has a great power to strengthen both intrinsic and extrinsic motivation to learn a foreign language, to expand one's experience and the acquisition of adaptive knowledge and to strengthen student's awareness of language input. As such, it may play a protective function against the lingering effects of negative emotions, such as foreign language anxiety, a fairly common and largely unwelcome emotion in the foreign language classroom. The two remaining components of enjoyment, physiological and expressing, embrace the bodily reaction to the positive emotional experience.

The crucial role of enjoyment in foreign language learning has been grounded on the Fredrickson's broaden-and-build theory of positive emotions (2001) as well as the control-value theory of achievement emotions (Pekrun, \& Linnenbrink-Garcia, 2014; Pekrun, Gotz, Titz, \& Perry, 2002). As to its conceptualisation, Foreign Language Enjoyment (FLE) can be described as "a complex emotion, capturing interacting dimensions of challenge and perceived ability that reflect human drive for success in the face of difficult tasks" (Deweale, \& MacIntyre, 2016, p. 216). FLE can be further conceptualised as a psychologically positive activating state, which is believed to propel the FL learner into action and strengthen the motivational processes. The duration of FLE is not that obvious, yet, taking into account its activity-focused nature, the duration of enjoyment is a relatively short one (lasting from a few seconds to a few minutes). What does not leave any doubt, in turn, is that FLE can be characterised by great intensity.

As to the effects of FLE on academic achievement, a number of tendencies can be displayed. First, FLE is positively correlated with students' academic achievement (Dewaele, \& Dewaele, 2018) and with their proficiency in a foreign language. It is due to the fact that a good command of a foreign language is linked with a greater control perception, particularly when FL learners 
attribute value to the FL they study (Piechurska-Kuciel, 2017). Another tendency is that female learners experience a higher level of FLE than their male peers (Dewaele, \& MacIntyre, 2014; Dewaele et al., 2017). Finally, in 2018, Gholam Khajavy and Masoud Mahmoodzadeh found that FLE constitutes a crucial factor in predicting learners' increased willingness to communicate (WTC).

Foreign language enjoyment is positively mediated by the classroom interactions, e.g. with friendly and supportive peers, as well as with FL teachers who are positive, encouraging, and who offer a variety of classroom activities which learners find interesting and challenging (Dewaele, \& MacIntyre, 2014; Pavelescu, \& Petric, 2018). In this vein, two dimensions of enjoyment can be distinguished: FLE related to the teacher (teaching practices, support, positive attitude, teacher's recognition) and FLE connected with the atmosphere in the FL classroom (peer interaction, positive atmosphere, positive engagement) (Li, Jiang, \& Dewaele, 2018). One more dimension that can be added to the two aforementioned, however no less important, is FLE- private coalescing around personal progress and development in the FL. The following sources of FLE- private can be distinguished: progress realisation, an excellent FL performance, the sense of pride of one's accomplishment, positive changes in the process of FL learning, etc. (Li, Jiang, \& Dewaele, 2018).

Taken as a whole, FLE is a desirable emotion, which operates as a driving force for the FL learning process, as it results in higher academic achievement, boosts motivation, and may play a protective function against negative emotions (MacIntyre, 2016). For that reason, FLE constitutes an educationally relevant emotion and might be requisite for all learners to unlock their full foreign language potential. In this sense, it can and should be treated as a legitimate, multipurpose 'tool' facilitating language learning and its role cannot be underestimated. What emerges is a complex picture of foreign language enjoyment, an underestimated and not fully explored emotion, thanks to which learning a FL might be more effective and acquisition of a FL greatly facilitated.

\section{FOREIGN LANGUAGE TEACHERS}

The role of the teacher in the foreign language classroom is not only limited to passing the linguistic information to students, spreading the knowledge of linguistics systems and teaching about FL culture, etc. It is far more important than that. The teachers are in charge of managing the emotional tenor of the classroom, creating a positive atmosphere in the FL group, establishing strong social connections among peers and, ideally, teaching with joy, optimism and passion (Dewaele et al., 2018). Thus, it is reasonable to believe that the psychological well-being of teachers provides the basis for their emotional and personal investment in teaching.

As it has been already mentioned, FL teachers, their teaching practices, the variety of teaching techniques they use, the support they express to their stu- 
dents, their positive appreciation and positive attitude to learners might all be perceived as one of the lynchpins of FLE experienced by students ( $\mathrm{Li}$, Jiang, \& Dewaele, 2018).

The starting point for the present article is that enjoyment is an emotion experienced not only by students but also by their educators, whose satisfaction is believed to be strongly connected to the enjoyment experience of their pupils, the progress they make and the pleasant atmosphere in the classroom (Piasecka, 2016). Several studies have reported that enjoyment, in comparison to pride, anger, anxiety, shame and boredom, is one of the most frequent discrete emotions experienced by teachers (Frenzel, 2014; Sutton, \& Wheatley, 2003) and that enjoyment dominates teachers' emotions in the classroom (Carson, 2006). Further, it has been found that enjoyment experienced by teachers is positively related to learners' enjoyment and the very effect of teachers' enjoyment on learners' enjoyment is mediated by teachers' enthusiasm (Frenzel, Goetz, Lüdtke, Pekrun, \& Sutton, 2009).

If perceived as a dominant emotion among educators, it is reasonable to believe that enjoyment may greatly facilitate the teaching process in a similar way to which it facilitates the learning process the students undergo. The question that remains unanswered is whether or not a student may derive joy from learning a foreign language if this process is stimulated by a teacher who does not enjoy teaching his/her subject. The experience of enjoyment, therefore, appears to be critical for both students (to learn) and for teachers (to teach FL more effectively).

\section{EMPIRICAL RESEARCH}

The primary objective of the present study was to investigate the level of foreign language enjoyment experienced by foreign language teachers in Poland while learning and teaching a FL. The secondary aim was to investigate the sources of foreign language enjoyment experienced by FL students, yet from the perspective of their educators.

The present study aims to address the following research questions:

RQ1: What is the level of foreign language enjoyment among foreign language teachers in Poland (while learning/ while teaching)?

RQ2: What is the effect of independent variables (gender, place of residence, years of experience, school type, a language being taught) on the level of Foreign Language teaching Enjoyment?

RQ3: What sources of FLE are indicated by FL teachers?

RQ4: What did FL teachers derive joy from while learning a FL?

RQ5: What (in teachers' opinions) do FL students derive joy from while learning a FL? 


\section{THE INSTRUMENT}

The main instrument of the study was a web-questionnaire. The participants of the study were asked to fill in an online questionnaire, which was preceded by a brief explanation of the general aim of the research. The participants filled the questionnaire voluntarily. All questions were formulated in the participants' mother tongue, that is to say in Polish.

The questionnaire comprised questions of both quantitative and qualitative nature. In the first part, the teachers were asked to answer the questions regarding their sociodemographic information (e.g. gender, place of residence, type of school they teach in, work experience, etc.). The subsequent part of the questionnaire included two scales.

The first one was a 10-item scale created for the purpose of the study. It was based on Pekrun's (2002) Learning Enjoyment Scale, however, adopted to the foreign language learning environment. All items in the scale were formulated in the past tense (e.g. "I looked forward FL classes," "Reflecting on the progress of my students made me happy," "I got physically excited when my learning was going well," "I studied more than required because I enjoyed FL much"). For the needs of the article, it was named Foreign Language Learning Enjoyment Scale.

The second was a Foreign Language Enjoyment Scale (developed by Dewaele, \& McIntyre, 2014) adapted to the foreign language teaching environment, which, for the needs of the present article received a working name of Foreign Language Teaching Enjoyment Scale.

The following part of the questionnaire aimed to assess the sources of foreign language enjoyment. The participants were provided with a list of 8 sources of enjoyment (e.g. teachers' attitude, positive atmosphere in the classroom, challenging material, learning real-life language) and they were asked to point to at least 1 and at most 3 aspects, which in their opinion have the greatest impact on their enjoyment experience. The participants had also an opportunity to suggest their own source of enjoyment which was not listed in the questionnaire. The reliability of the scale was equal to $\mathrm{a}=.85$.

The final part of the questionnaire included two questions of a qualitative nature. First, the teachers were asked to describe one specific moment in their own foreign language learning experience which they derived joy from. In the subsequent part, they were asked to answer a similar question, yet, in reference to their foreign language students.

\section{PARTICIPANTS}

The vast majority of all the participants constituted female teachers. A total of 89 participants ( 63 females, 26 males) completed the web-questionnaire. All of them were foreign language (FL) teachers and their experience in the profession ranged from one year to more than 20 years. 38 participants $(42.7 \%)$ have been teaching a FL for less than 5 years, 17 participants (19.1\%) 5-10 years, 20 
participants $(22.5 \%)$ 11-20 years and 14 respondents $(15.7 \%)$ have been teaching for more than 20 years. All of the participants were of Polish nationality and completed the questionnaire in their mother tongue.

Regarding the participants' place of residence: more than a half (49 people, $55.1 \%$ ) of all the participants teach FL in the school located in a city (over 50,000 citizens); 27 participants (30.3\%) teach in a town (from 2,500-50,000 citizens), and 13 teachers (14.6\%) teach in a village (with less than 2,500 citizens).

There was a quite even distribution of the types of school the participants were teaching a foreign language in: only 3 out of all 89 participants teach a FL in the kindergarten (3.4\%); 29 teachers teach in primary school (32.6\%); 25 in secondary grammar high school $(28.1 \%) ; 8$ in technical school $(9 \%)$. There was one participant who declared teaching a FL at the tertiary education level. Eventually, over a quarter of all the participants $(25.9 \%, 23$ teachers) of the study declared themselves as teaching in the private sector of education, teaching FL to students at different educational levels in private language schools.

As to the languages being taught, the vast majority of the participants taught English as an FL (38 respondents, 42.7\%); the second largest group constituted teachers of Spanish as an FL (14 teachers, 15.7\%), the remaining groups comprised of FL teachers of German (12 teachers, 13.5\%), Russian (12, $13.5 \%)$, French (8 participants, $9 \%$ ) and Italian as a FL (1, 1.1\%). The remaining 4 teachers $(4.5 \%)$ declared that they were teaching more than two FLs.

Regarding the level of education, the vast majority of the participants had a higher education. There were 11 FL teachers (12.4\%) holding BA Degree, and 70 teachers (78.6) holding MA; 1 participant declared being at the PhD level. There were 7 participants $(7.9 \%)$ who have not completed their higher education yet. Those were the philological students who were teaching a FL in the private sector of education.

\section{VARIABLES}

The independent variables in the present study were as follows: participants' gender, type of foreign language being taught, place of residence, level of education, years of teaching experience, and type of school the participants taught in.

There were two main dependent variables measured in the present study: teachers' foreign language learning enjoyment and foreign language teaching enjoyment. The operational definition of teachers' foreign language learning enjoyment was reflected by the number of points achieved on the Learning Enjoyment Scale adapted to the FL environment (5-point Likert scale ranging from "I absolutely do not agree" to "I fully agree"). All items on the scale were phrased positively and were formed in the past tense in order to reflect the retrospective nature of the questions. The Cronbach alpha was .83 .

The operational definition of foreign language teaching enjoyment, in turn, was reflected by the number of points achieved on the FLE Scale adapted to the 
needs of the study. Those were the Likert scale responses to a shortened version of Foreign Language Enjoyment Scale adapted to the context of teaching, not learning. In total, the scale included 17 questions, all phrased positively. Foreign Language Teaching Enjoyment was measured through such items as "I enjoy teaching a FL," "I have fun while teaching a FL," "I feel proud of my students' accomplishments in the FL." The Cronbach alpha was .88.

\section{ANALYSES}

Data collection lasted one week. The data were computed by means of the statistical program STATISTICA, with the main operations being descriptive statistics (means and $S D$ ) and an inferential statistics operation: a t-test for independent samples (between between-group comparison) and one-way ANOVAs. T-test was used to compare the performance of two groups (males/ females) on a scale measuring their FL learning Enjoyment and FL teaching Enjoyment. One-way ANOVA was be used to compare the performance of more than two groups (years of experience, language being taught, etc.).

\section{RESEARCH RESULTS - QUANTITATIVE}

The analysis of the results for all the participants of the present study revealed a higher level of FL learning Enjoyment $(\mathrm{M}=4.42, \mathrm{SD}=0.49)$ than of Foreign Language teaching Enjoyment $(\mathrm{M}=4.19, \mathrm{SD}=0.34)$. Table 1 below presents these results in greater detail.

\section{Table 1.}

Mean, SD for FL learning Enjoyment and FL teaching Enjoyment for all the participants and for males and females separately.

\begin{tabular}{|c|c|c|c|c|c|c|c|}
\hline \multirow[t]{2}{*}{ Variable } & \multicolumn{2}{|c|}{ All $(\mathrm{N}=89)$} & \multicolumn{2}{|c|}{ Females $(\mathrm{N}=63)$} & \multicolumn{2}{|c|}{ Males $(\mathrm{N}=26)$} & \multirow[t]{2}{*}{$\mathrm{T}$} \\
\hline & M & $S D$ & $\mathrm{M}$ & $S D$ & M & $S D$ & \\
\hline FL learning Enjoyment & 4.42 & 0.49 & 4.50 & 0.42 & 4.23 & 0.58 & $2.42^{*}$ \\
\hline FL teaching Enjoyment & 4.19 & 0.34 & 4.21 & 0.27 & 4.14 & 0.47 & $0.89 * *$ \\
\hline
\end{tabular}

${ }^{*} \mathrm{p}=0.016, \mathrm{p}^{* *}=0.379$

What emerges from the table above is that there is a significant gender difference in the Mean Scores for enjoyment. More specifically, the results of the study revealed a significant gender difference in the FL learning Enjoyment with female teachers experiencing higher level of enjoyment $(M=4.50$, $\mathrm{SD}=0.42)$ than male teachers $(\mathrm{M}=4.23, \mathrm{SD}=0.58)$. There was also a slight gender difference in terms of FL teaching Enjoyment, however not statistically significant. Figure 1 below shows a visual representation of the data. 


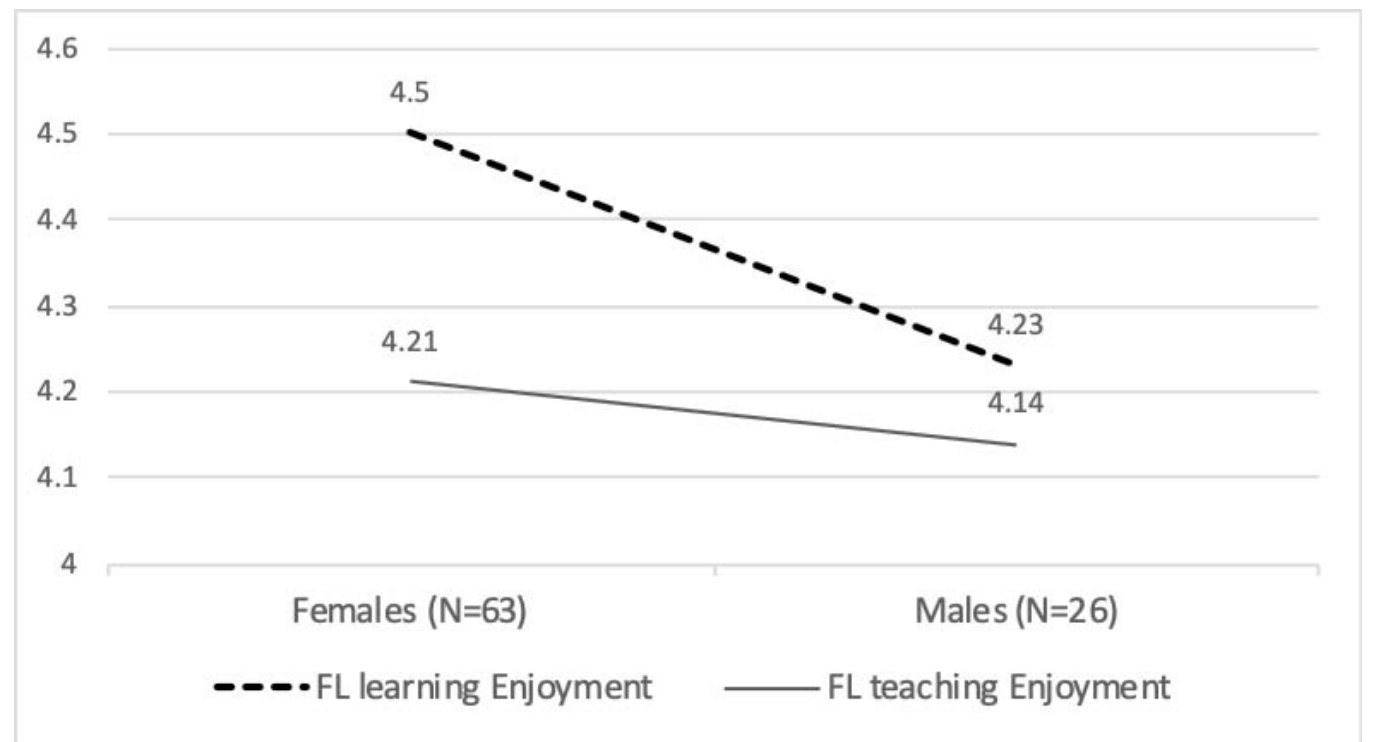

Figure 1.

FL learning Enjoyment and FL teaching Enjoyment form males and females.

For the needs of the present study, from now on the analysis of results will be focused on Foreign Language teaching Enjoyment primarily. Among the group of teachers participating in the present study, the highest level of Foreign Language teaching Enjoyment was experienced by teachers of Russian as a FL $(\mathrm{M}=4.34 ; S D=0.28)$ and Spanish $(\mathrm{M}=4.29 ; S D=0.24)$, and the lowest by the teachers of English $(M=4.15 ; S D=0.37)$. Nevertheless, due to unequal sample sizes, caution must be applied as the findings might not be generalisable. One-way ANOVA did not display any statistically significant differences between the groups $(F(6,82)=.40923, p=.87)$. Figure 2 below shows a visual representation of the data.

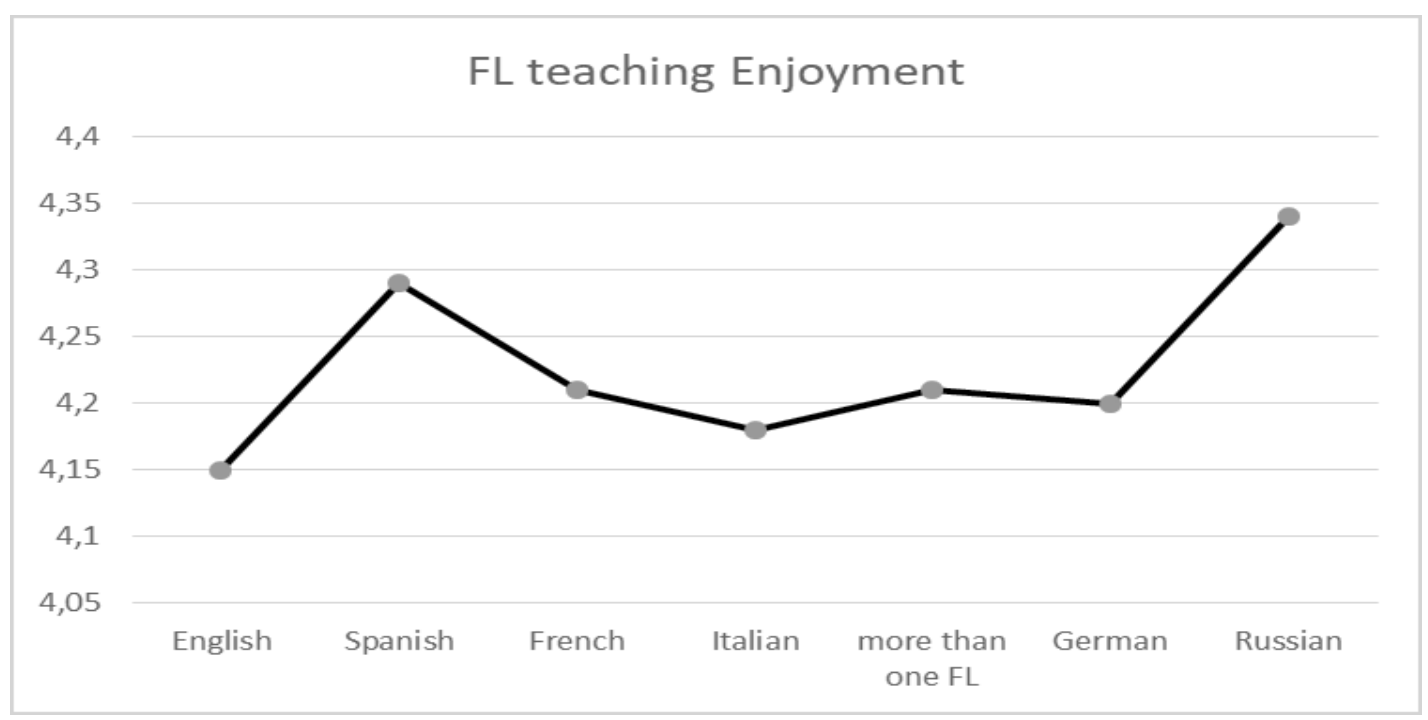

Figure 2.

FL teaching Enjoyment according to the FL. 
Journal of Education Culture and Society No. 2_2019

It is now time to analyse these results from the perspective of all the remaining independent variables. The results are presented and summarized in Table 2 below.

\section{Table 2.}

FL teaching Enjoyment according to independent variables

Variables

\begin{tabular}{llll} 
& & M & $S D$ \\
\hline Gender & female & 4.21 & 0.27 \\
Place of residence & male & 4.14 & 0.47 \\
& village & 4.13 & 0.41 \\
& town & 4.29 & 0.25 \\
& city & 4.17 & 0.33 \\
& student & 4.38 & 0.23 \\
Years of experience & 4.22 & 0.31 \\
& BA & 4.19 & 0.33 \\
& MA & 4.01 & \\
SchD student* & less than 5 year & 4.12 & 0.37 \\
& 5-10 years & 4.33 & 0.30 \\
& 11-20 years & 4.22 & 0.26 \\
& more than 20 years & 4.24 & 0.24 \\
& kindergarten & 4.00 & 0.41 \\
& primary school & 4.21 & 0.33 \\
& secondary grammar HS & 4.20 & 0.22 \\
& vocational school & 4.08 & 0.25 \\
& university* & 4.68 & \\
& private language schools & 4.24 & 0.40 \\
\hline
\end{tabular}

*only one participant

As shown in the table above, the level of FL teaching Enjoyment is at a relatively high level regardless of all independent variables investigated in the present study. A series of One-way ANOVAs have shown lack of significant effect of any of the independent variables on the level of participants' FL teaching Enjoyment. The results were as follows: in the case of participants' gender: $F(1,87)=.38230, p=.54$; their place of residence: $F(2,86)=1.6135, p=.205$; their level of education $\mathrm{F}(3,85)=.82838, \mathrm{p}=.49$, years of teaching experience: $\mathrm{F}(3$, $85)=.7498, p=.16$; and type of school the participants teach in: $F(5,83)=.97471$, $\mathrm{p}=.44$. More interesting, however, appears to be the analysis of the qualitative part of the data. Let us now take a closer look at these results.

\section{RESEARCH RESULTS - QUALITATIVE}

The participants of the study were provided with a list of eight sources of FLE enjoyment, which in their opinion contribute the most significantly to their students' enjoyment. The participants pointed to at least one and at most 
three sources of enjoyment. The results revealed that 68 out of total 89 participants $(76.4 \%)$ pointed to the teacher's attitude as one of the main factors that mainly affect students' foreign language enjoyment. Then, 52 out of 89 $(58.4 \%)$ claimed that it is an interesting topic of the lesson, 48 out of $89(53.9 \%)$ pointed to learning real-life language (that would be useful in everyday life outside the school). Subsequently, 46 out of 89 (51.7\%) participants marked teachers' sense of humour and a positive atmosphere in the classroom. The least frequent source of FL the teachers pointed to were demanding/challenging activities (30 responses out of total 89,33.7\%) and specific classroom activities, e.g. games, role plays, funny activities (27 out of $89,30.3 \%$ ). The results are summarized in Table 3 below.

Table 3.

Sources of FLE and the frequency of responses

\begin{tabular}{ll}
\hline Source & Number of responses \\
\hline Teacher's attitude & $68(89)$ \\
Interesting topic of the lesson & $52(89)$ \\
Learning real-life language & $48(89)$ \\
Teacher's sense of humour & $46(89)$ \\
Positive atmosphere in the classroom & $46(89)$ \\
Possibility of self-development & $43(89)$ \\
Demanding/challenging activities & $30(89)$ \\
Games, play-roles, funny activities & $27(89)$ \\
\hline
\end{tabular}

According to the participants of the present study, students experience enjoyment while learning a foreign language once the atmosphere in the classroom is positive and the teacher laughs, has got a positive attitude to teaching, and creates the foreign language classroom into a positive and emotionally safe place. It seems that the participants of the present study are well aware of the fundamental role they play in the positive emotional experiences of their pupils.

There were two open-ended questions the participants were asked to answer, both aiming at investigating the sources of FLE according to participants' description. The first one referred to an enjoyable episode in the FL classroom which the teachers experienced themselves while being FL students. The second one referred to an enjoyable episode in the FL classroom as well, yet the participants were asked about their students' experiences. Teachers' accounts on enjoyment from both perspectives will be now presented respectively. Following the coding approaches of Dewaele and McIntyre (2014; 2018), the emotion-related episodes were coded into three main categories: FLEteacher, FLE-Atmosphere, FLE-private. The results will be now analysed with reference to the aforementioned categories.

Only 42 out of total 89 participants responded to the first question. The participants' accounts were divided into three coding categories that may represent the sources of FLE. Table 4 below clearly illustrates the collected and cate- 
gorised data, provides the examples and presents the frequency of mentions by the participants.

Table 4.

Sources of teachers' personal learning enjoyment, examples and frequency of mentions by the participants $(\mathrm{N}=42)$

\begin{tabular}{lll}
\hline Coding category & Examples & Frequency \\
\hline FLE-Teacher & - teacher's sense of humour and jokes; positive 12/42 \\
& attitude to students; recognition and appreciation. \\
& - teaching strategies, methods and techniques; \\
& specific classroom activities: games, role plays, \\
& singing songs, storytelling \\
\hline FLE-Atmosphere & $\begin{array}{l}\text { positive relationship with peers, mutual help, nice 6/42 } \\
\text { atmosphere, smiling, laughing }\end{array}$ \\
\hline FLE-Private & $\begin{array}{l}\text { pride in one's accomplishment, sense of self- 24/42 } \\
\text { development, real-life use of language, getting good } \\
\text { marks, teacher praise in front of a class or work; } \\
\text { preparing to, taking part in and finally winning the } \\
\text { competition, learning more than required }\end{array}$ \\
\hline
\end{tabular}

Among the first category, teachers' positive attitude to learners, their appreciation was most frequently mentioned sources of enjoyment. One participant commented on how positive attitude of her teachers encouraged her to learn English: "I was learning a FL more than 30 years ago. At that time, the classes were overcrowded and there was no place for games and fun activities. What I remember the most is the smile and positive attitude of my professor, which motivated me to hard work" (female, teacher with more than 20 years of experience in teaching English as a FL in secondary grammar high school).

The remaining sources of FLE in this category were mostly related to the teacher's practices in the FL classroom, variety of teaching strategies and stimulating specific classroom activities (preparing projects about FL culture, playing games and role-plays, learning by means of songs and drama, telling stories, etc.).

Among the category of FLE-atmosphere, positive atmosphere in the FL classroom and a good relationship with peers (laughing, smiling, having fun) were mentioned the most frequently as the source of FLE. One participant described the atmosphere in her FL classroom in the following way: "we felt a strong sense of community, support and team spirit" (female, teacher of Russian as a FL, 5-10 years of experience).

And another one emphasised that a positive and relaxed atmosphere in the FL did not exclude learning, claiming that: "there was a homely and relaxed atmosphere in the FL classroom, we could talk about anything we wanted, under one condition, it needed to be in the FL" (female, Spanish teacher with 5-10 years of teaching experience). 
The participants of the study the most frequently mentioned the private dimension of FLE. Among this category, the participants often felt enjoyment when they had a good language performance in class and they felt pride in their accomplishment, e.g. "I felt amazing when I was able to precisely express my thoughts in a foreign language" (female, English teacher in the private school). In a significant number of cases the participants used the word pride/ proud in order to reflect their sense of satisfaction and accomplishment they felt in the FL classroom: "I was proud of myself when I was praised in front of the classroom" (female, English teacher in primary school); "I remember the pride I felt when I used the language in the real-life situation for the first time" (female, French teacher in the primary school); "the sense of pride when I was the only one in the classroom who knew the answer" (male, English teacher in secondary grammar high school); "I was proud of myself when I knew the expression, which the teachers were unfamiliar with" (female, English teacher, technical vocational school).

The second open-ended question also aimed to investigate the sources of FLE according to three categories. Nonetheless, this time, the participants of the study were asked not about their own but about their students' experiences. In other words, this question enabled the researcher to investigate what joy students' derive from while learning a foreign language, yet, from the perspective of teachers. 45 out of total 89 participants responded to that question. Table 5 below represents the collected and categorised data.

\section{Table 5.}

Learners' sources of FLE according to teachers, examples and frequency of mentions by the participants $(\mathrm{N}=45)$

\begin{tabular}{lll}
\hline Coding category & Examples & Frequency \\
\hline FLE-Teacher & $\begin{array}{l}\text { teachers' dynamism, positive emotions, } \\
\text { feedback, lack of boredom, variety of teaching } \\
\text { techniques (e.g. songs, quizzes, charades, role- } \\
\text { plays, flashcards, skype conversation); involving } \\
\end{array}$ & \\
& $\begin{array}{l}\text { learners in exciting/ challenging games); } \\
\text { encouraging students to a friendly rivalry }\end{array}$ & \\
\hline FLE- Atmosphere & $\begin{array}{l}\text { positive relationship with peers, mutual help, } \\
\text { nice atmosphere, smiling, laughing, integration }\end{array}$ & $9 / 45$ \\
\hline FLE-Private & $\begin{array}{l}\text { Pride, joy and excitement about one's } \\
\text { accomplishment, sense of self-development, } \\
\end{array}$ & real-life use of language, overcoming challenges, \\
& $\begin{array}{l}\text { taking part in a competition, winning the FL } \\
\text { competition, learning more than required }\end{array}$ & \\
\hline
\end{tabular}

The participants of the study most frequently mentioned the teacher's dimension of FLE. Among this category, the participants enumerated a variety of teaching methods and techniques which they incorporate while teaching and which, in their opinion, constitute the source of positive emotions among their students. 
The second in frequency was the private dimension of FLE. Similar to the previous question, the participants pointed most often to pride, joy and excitement of their students at the moment of accomplishment and excellent FL performance. Dealing with challenging tasks, taking part in FL competition were other main sources of FLE.

The participants of the present study pointed least frequently to the social dimension of FLE, that is FLE-Atmosphere. It is worth to allude to the words of one participant commenting on a game competition:

The students really enjoyed the game aimed at practising conditional clauses. Although the game was difficult, the students were really absorbed while playing. They were shouting with joy once they did something correctly. If not, they were slightly disappointed. In the end, everyone was satisfied and achieved a small success. They left the class with smiles on their faces and they wanted to play again. Nevertheless, such a situation did not take place in each and every class. In those classes where the atmosphere is not good and the relationships between peers are stormy, the game was not successful (English teacher, primary school, less than five years of experience).

In a similar vein, FLE was depicted by another participant of the study (teacher of English at the tertiary educational level). The participant claimed as follows: "when they [the students] faced a grammatical problem which at the beginning appeared to be intractable for them. After some time of dealing with it, they found the answer and had a sense of enlightenment. They felt excited and proud of themselves, which motivated them for further work".

These two examples highlight some core truths about foreign language enjoyment. First, taking into account its private dimension, FLE is an emotion that is not trivial and frivolous, it is not experienced at the moment of dealing with easy tasks, but with those that pose a moderate challenge, require mental effort. In this sense, enjoyment is a reflection of learners' drive for success in the face of difficult foreign language tasks (Deweale, \& MacIntyre, 2016).

It is the joy at the moment of taking the challenge, of dealing with a demanding task and eventually, it is the sense of satisfaction and pride in one's accomplishment which motivates for further work. Taking into consideration its social dimension, in turn, enjoyment appears to be strongly moderated by the relationship among peers students, the atmosphere created in the classroom, positive rivalry and the social bonds established in the FL. Finally, it might be determined by the relationship with teachers, their dynamism, a variety of teaching techniques, positive attitude and enthusiasm, their support and appreciation. A concluding comment for what has been suggested might be vividly represented by the quotation of one of the participants of the study: "Even the most difficult grammatical concept can be presented in an interesting way. What is absolutely crucial? Positive emotions, teacher's dynamism and a variety of teaching techniques" (French teacher in the primary school, female). 


\section{DISCUSSION}

The present study aimed to answer five research questions. The results will be now analysed and discussed in line with these questions.

The first research question aimed to investigate the level of FLE among foreign language teachers in Poland. At the beginning, the results will be discussed for the Foreign Language learning Enjoyment (retrospective accounts of the teachers when they were FL learners themselves).

Not unexpectedly, the results of the study reveal that Polish foreign language teachers experienced a relatively high level of foreign language learning enjoyment. Due to the fact that, to the best of my knowledge, this is the first study aimed at investigating the level of enjoyment experienced by teachers, these results cannot be compared to any other studies. Nonetheless, these results are not surprising for two reasons. First, foreign language teachers can boast high expertise in a FL and it has been found that high proficiency and mastery in a FL results in high FLE (Dewaele, \& MacIntyre, 2014; 2016; 2018). Second, it appears to be a matter of course that those students who enjoy language learning more significantly than others, decide to continue their foreign language learning to the level of tertiary education and, more often than not, use the FL as a tool to work in their future, e.g. by becoming FL teachers. The results reveal a significant gender difference in Foreign Language Learning Enjoyment in favour of the female participants. These results dovetail those observed in the previous studies on FLE with female learners experiencing a significantly higher level of FLE than their male peers (Dewaele, \& MacIntyre, 2014; Radwan, 2014; Dewaele, Witney, Saito, \& Dewaele, 2018).

As the Foreign Language teaching Enjoyment, the level of enjoyment is on a lower level than Foreign Language learning Enjoyment. Nevertheless, due to two slightly different tools (scales) adopted for the measurement of these variables, caution must be applied while making any comparison. In the case of this type of enjoyment, there are no significant gender differences.

The second research question examined the effects of independent variables on the level of FL teaching Enjoyment. The results reveal that none of the investigated variables have a significant effect on the level of Foreign Language Teaching Enjoyment. Optimistically, it might be stated that foreign language teachers experience a high level of teaching enjoyment, regardless of their gender, place of residence, years of experience, school type, and the type of the language they teach.

The following research question aimed to investigate the sources of FLE which, in the teachers' opinions, have the most significant effect on their students' enjoyable experiences in the classroom. The results reveal that the vast majority of the teachers perceive themselves and their positive attitude to students to be the strongest predictors for their learners' enjoyment. It seems that foreign language teachers are aware of the fact that they play a vital role in the foreign language learning process, not only because of their expertise but also because of emotions that they may evoke in students, the atmosphere they 
create in the classroom, and useful and interesting lesson content they provide their learners with. In very general terms, they are in charge, or more adequately, they have the privilege of influencing their students' emotions in the FL classroom. Thus, the effective foreign language teacher is not only the one who may boast great command of a foreign language, methodology - system of practices and procedures that a teacher uses to teach-but, first and foremost, the atmosphere and the relationship created in the FL classroom as it may impact the learners' attitude to life-long learning.

The two final research questions were of a strictly qualitative nature and aimed to investigate FLE according to three main categories: FLE-Private, FLE-Atmosphere, FLE-social. The distribution of these categories was significantly different when the teachers' described their own experiences and those of their learners. Describing their own experiences, the private dimension of enjoyment was mentioned the most frequently. The vast majority of the participants emphasised the joy they derived while overcoming FL difficulties, giving an excellent FL performance, taking part in extra-curricular activities and FL competitions, all of which made them proud, satisfied and fulfilled.

Asked about their students' experiences, in turn, it was the teacher who was indicated as the main source of FLE the most frequently. Teachers' dynamism, positive attitude (teacher's praise) and a variety of teaching techniques are just a few examples of the teacher's dimension of FLE indicated by the participants of the study. Regardless of the question being posed, the atmosphere in the FL classroom (peer interaction, integration, positive climate in the classroom) was indicated the least frequently.

\section{CONCLUSIONS AND IMPLICATIONS}

The present study aimed to investigate enjoyment in the foreign language classroom, which among the gamut of other positive emotions experienced in the foreign language classroom deserves a thorough investigation due to its critical role in the achievement settings. The originality of the present study lies in the choice of a mixed-method approach (both of a qualitative and quantitative nature) using a relatively large sample in a field characterised by case studies. To the best of my knowledge, this is the first study on foreign language enjoyment among teachers within the Polish educational context.

The results of the present study indicate that foreign language teachers in Poland experience a high level of both learning and teaching enjoyment, regardless of their gender, the language they teach, level of education and the type of the school they teach in.

A qualitative analysis of participants' emotional experiences in the FL classroom confirmed previous research on FLE to a certain degree. That is, foreign language enjoyment is more related to learner-internal and teacher-specific variables than to the behaviour of peers and the atmosphere created in the FL classroom. 
There are a number of pedagogical implications that may arise from this study. The first one is that the role of the teacher in the foreign language classroom is not only limited to passing the linguistic information to the students and/or familiarising learners with the culture of the FL, etc. Once assumed that teachers are responsible for managing the emotional tenor of the foreign language classroom, their positive attitude and more specifically their appreciation and recognition may constitute a tool that can be a powerful motivator for foreign language students. As revealed by the participants of the present study, positive relationship with a FL teacher, who is friendly, passionate, humorous and supportive, is one of the strongest predictors of foreign language enjoyment. Teacher support and positive classroom should be therefore a commonplace for all the students, whether those enjoying learning or not. Teachers' appreciation in front of the classroom is also highly recommended as it may lead to the feelings of pride and self-satisfaction, which further motivate students to learn and develop.

One cannot forget about the private dimension of foreign language enjoyment derived from dealing with an activity that requires heightened attention and mental effort from the students. Thus, FL teachers should do their best to provide their students with novel and challenging tasks that arouse their curiosity, generate interest and strengthen intrinsic motivation. Further, teachers should give learners a sense of autonomy and allow them, from time to time, to make choices of what they want and need to learn.

Eventually, since it is well-known that foreign language learning is the process particularly prone to anxiety, which constitutes a threat to not only to the performance in the FL but also to learners' self-concept and their identity, foreign language educators should create a less threatening environment in the FL classroom. This could be done by acknowledging students' discomfort, showing support, allowing learners to make mistakes, or simply helping students to develop more realistic expectations for foreign language learning.

\section{LIMITATIONS}

The generalisability of these results might be subject to certain limitations. The reader should bear in mind that the study is based on the teacher's response who filled out the questionnaire voluntarily. This, in turn, for some researchers, may have led to biased results. Second, the participants filled out the questionnaire online which gave the researcher a lack of control over the procedure of the data collection. Further, qualitative data were analysed only by the author of the present study. To avoid biased results, an independent researcher with the same coding categories is recommended. For a more complete understanding of the nature of enjoyment in the FL environment, data triangulation is strongly recommended, i.e. the investigation of this particular emotion from the perspective of students and teachers simultaneously, ideally, incorporating both quantitative and qualitative approach (mixed-method approach). 


\section{REFERENCES}

1. Ainley, M., \& Hidi, S. (2013). Interest and enjoyment. In: R. Pekrun, \& Lisa Linnenbrink-Garcia (Eds.), International handbook of emotions in education (pp. 205-220). New York: Routledge.

2. Carson, R. L. (2006). Exploring the episodic nature of teachers' emotions as it relates to teacher burnout (Unpublished doctoral dissertation), Purdue University, IN, USA.

3. Daubney, M., Dewaele, J. M., \& Gkonou, C. (2017). Introduction. In: J. M. Dewaele, C. Gkonou, \& M. Daubney (Eds.), New insights into language anxiety: Theory, research and educational implications (pp. 1-10). Bristol: Multilingual Matters.

4. Dewaele, J. M., \& MacIntyre, P. (2014). The two faces of Janus? Anxiety and enjoyment in the foreign language classroom. Studies in Second Language Learning and Teaching, 4(2), 237-274.

5. Dewaele, J. M., \& MacIntyre, P. (2016). Foreign language enjoyment and foreign language classroom anxiety. The right and left feet of FL learning? In: P. MacIntyre, T. Gregersen, \& S. Mercer (Eds.), Positive psychology in SLA (pp. 147-167). Bristol: Multilingual Matters.

6. Dewaele, J. M., MacIntyre, P., Boudreau, C., \& Dewaele, L. (2016). Do girls have all the fun? Anxiety and enjoyment in the foreign language classroom. Theory and Practice of Second Language Acquisition, 2(1), 41-64.

7. Dewaele, J. M., Witney, J., Saito, K., \& Dewaele, L. (2017). Foreign Language Enjoyment and Anxiety: The effect of teacher and learner variables. Language Teaching Research. Retrieved from http://journals.sagepub.com/doi/10.1177/1362168817692161.

8. Dewaele, J. M., Franco M. A., \& Saito, K. (2019). The effect of perception of teacher characteristics on Spanish EFL Learners' Anxiety and Enjoyment. The Modern Language Journal, 103(2), $412-427$.

9. Fredrickson, B. L. (2001). The role of positive emotions in positive psychology. The American Psychologist, 56(3), 218-226.

10. Fredrickson, B. L. (2004). The broaden-and-build theory of positive emotions. Philosophical Transactions of the Royal Society B: Biological Sciences, 359(1449), 1367-1378.

11. Frenzel, A. C. (2014). Teacher emotions. In: R. Pekrun, \& L. Linnenbrink-Garcia (Eds.), International handbook of emotions in education (pp. 495-496). New York: Routledge.

12. Frenzel, A. C., Goetz, T., Lüdtke, O., Pekrun, R., \& Sutton, R. E. (2009). Emotional transmission in the classroom: Exploring the relationship between teacher and student enjoyment. Journal of Educational Psychology, 101(3), 705-716.

13. Hagenauer, G., \& Hascher, T. (2014). Early adolescents' enjoyment experienced in learning situations at school and its relation to student achievement. Journal of Education and Training Studies, 2(2), 20-30.

14. Khajavy, G. H., \& Mahmoodzadeh, M. (2018). Towards Conceptualizing Language Learning Curiosity in SLA: An Empirical Study. Journal of Psycholinguistic Research. Retrieved from https://www.researchgate.net/publication/328003204_Towards_Conceptualizing_Language_Learning_Curiosity_in_SLA_An_Empirical_Study.

15. Li, Ch., Jiang, G., \& Dewaele, J. M. (2018). Understanding Chinese high school students' foreign language enjoyment: Validation of the Chinese version of the foreign language enjoyment scale. System, 76, 183-196.

16. MacIntyre, P. D. (2016). So far so good: An overview of positive psychology and its contributions to SLA. In: D. Gabryś-Barker, \& D. Gałajda (Eds.), Positive psychology perspectives on foreign language learning and teaching (pp. 3-20). Berlin/Heidelberg, NY: Springer.

17. MacIntyre, P. D., Gregersen, T., \& Mercer, S. (Eds.). (2016). Positive psychology in SLA. Bristol, UK: Multilingual Matters.

18. MacIntyre, P. D., \& Mercer, S. (2014). Introducing positive psychology to SLA. Studies in Second Language Learning and Teaching, 4, 153-172.

19. Oades-Sese, G. V., Matthews, T. A., \& Lewis, M. (2014). Shame and pride and their effects on student achievement. In: R. Pekrun, \& L. Linnenbrink-Garcia (Eds.), International Handbook of Emotions in Education (pp. 246-264). New York: Routledge.

20. Oxford, R. L. (2015). Emotion as the amplifier and the primary motive: Some theories of emotion with relevance to language learning. Studies in second language learning and Teaching, 5(3), 371.

21. Pavelescu, L., \& Petric, B. (2018). Love and enjoyment in context: Four case studies of adolescent EFL learners. Studies in Second Language Learning and Teaching. 8, 73-101. 
22. Pekrun, R. (2000). A social cognitive, control-value theory of achievement emotions. In: J. Heckhausen (Ed.), Motivational psychology of human development (pp. 143-163). Oxford, England: Elsevier.

23. Pekrun, R., Goetz, T., \& Titz, W. (2002). Academic Emotions in Students' Self-Regulated Learning and Achievement: A Program of Qualitative and Quantitative Research. Educational Psychologist 37(2), 91-106.

24. Pekrun, R. (2006). The control-value theory of achievement emotions: Assumptions, corollaries, and implications for educational research and practice. Educational Psychology Review, 18(4), 315-341.

25. Pekrun, R., \& Perry, P. (2014). Control-Value Theory of Achievement Emotions. In: R. Pekrun, \& L. Linnenbrink-Garcia (Eds.), International Handbook of Emotions in Education (pp. 120-141). New York: Routledge.

26. Pekrun, R., Frenzel A. C., \& Goetz, T. (2007). The control-value theory of achievement emotions: An integrative approach to emotions in education. In: P. Schultz, \& R. Pekrun (Eds.), Emotion in Education (pp. 13-36). Amsterdam: Academic Press.

27. Piasecka, L. (2016). Teaching Matters: Enjoyment and Job Satisfaction. In: D. Gałajda, P. Zakrajewski, \& M. Pawlak (Eds.), Researching Second Language Learning and Teaching from a Psycholinguistic Perspective (pp. 167-182). Cham: Springer.

28. Piechurska- Kuciel, E. (2017). L2 or L3? Foreign Language Enjoyment and Proficiency. In: D. Gabryś-Barker, D. Gałajda, A. Wojtaszek, \& P. Zakrajewski (Eds.), Multiculturalism, Multilingualism and the Self. Studies in Linguistics and Language Learning (pp. 97-111). Cham: Springer. 